\title{
Analysis of ventricular synchrony: A complex puzzle
}

\author{
Guillermo Romero-Farina, MD, PhD, FESC, FASNC, \\ and Santiago Aguadé-Bruix, $M D^{b}$ \\ a Cardiology Department, Hospital Universitari Vall d'Hebron, Institut de Recerca (VHIR), \\ Universitat Autònoma de Barcelona, Barcelona, Spain \\ b Department of Nuclear Medicine, Hospital Universitari Vall d'Hebron, Institut de Recerca \\ (VHIR), Universitat Autònoma de Barcelona, Barcelona, Spain
}

Received Feb 27, 2018; accepted Feb 27, 2018

doi: $10.1007 / \mathrm{s} 12350-018-1252-5$

\section{See related article, pp. 1650-1658}

The following editorial was focused on the most relevant points of the article by Malik et al.: ${ }^{1}$ firstly, normal cut-off values of phase analysis parameters and different variables that influence in the ventricular synchrony analysis; secondly, the impact of the duration of type II diabetes mellitus on left ventricular mechanical synchrony analysis; thirdly, the repercussions on the cardiac function of the diseases associated with diabetes mellitus (DM), and its complications; and fourthly, a normal gated SPECT definition.

In the last 13 years, we have a new tool in the area of nuclear cardiology called analysis of left ventricle synchrony. Since 2005, several articles ${ }^{2-20}$ have been published in relation to the normal cut-off values (Table 1), and diagnosis and prognosis (Table 2). From a physiological point of view, the study of the mechanical synchronization of the ventricles is very complex. Among the different publications, there is a general agreement between the average values and the cut-off values normality obtained; however, in spite of that they are not exactly concordant. This is due to the fact that these cut-off values depend on multiple

Reprint requests: Guillermo Romero-Farina MD, PhD, FESC, FASNC, Cardiology Department, Hospital Universitari Vall d'Hebron, Institut de Recerca (VHIR), Universitat Autònoma de Barcelona, Paseo Vall d'Hebron 119-129, 08035, Barcelona, Spain; guiromfar@gmail.com,guirom@telefonica.net

J Nucl Cardiol 2019;26:1659-66.

$1071-3581 / \$ 34.00$

Copyright (C) 2018 American Society of Nuclear Cardiology. variables, which are difficult to control in the statistical analysis (Figure 1). Until now, all the information provided by different groups of researchers have taught us that these influential variables can be grouped into four main categories (Figure 1): type of software, type of statistical methodology to find the appropriate cut-off values, the moment that images are acquired, and clinical patient data. But probably, as experimental studies show $^{21}$, the most complex thing to control is the effect of the intrinsic myocardial properties on ventricular synchrony, which are specific to each patient.

Through different mechanisms, patients with DM have high cardiovascular morbidity and mortality. The left ventricular diastolic dysfunction, ${ }^{22,23}$ systolic dysfunction, ${ }^{24}$ and left ventricular mechanical dyssynchrony (LVMD) ${ }^{1}$ are frequent.

In this issue of Journal of Nuclear Cardiology, Malik et al. evaluated retrospectively 146 consecutive patients with normal gated SPECT-MPI. ${ }^{1}$ LVMD was determined by the cut-off values (mean $+2 \mathrm{SD}$ ) observed for phase standard deviation (SD) and phase bandwidth (BW) from the control subjects. LVMD was detected in 24 (28\%) DM patients with the pre-defined cut-off values for SD (>10.8) and BW (> 35.6) derived from the controls. Hyperlipidemia, overweight/obesity, duration of DM, and its long-term complications were independently associated with LVMD, with long-term complications being the highest risk factor (OR 28.00; $p<0.001)$. The authors concluded that the evolution time of the patients with type II DM affects the left ventricular mechanical synchrony.

In this study, long-term type II diabetes complications (nephropathy, neuropathy, neuropathy, and/or retinopathy) were present in $27.9 \%(24 / 86)$ of patients, and 18 of them $(18 / 24,75 \%)$ had LVMD. Therefore, the cause and the degree of LVMD is not only due to the 


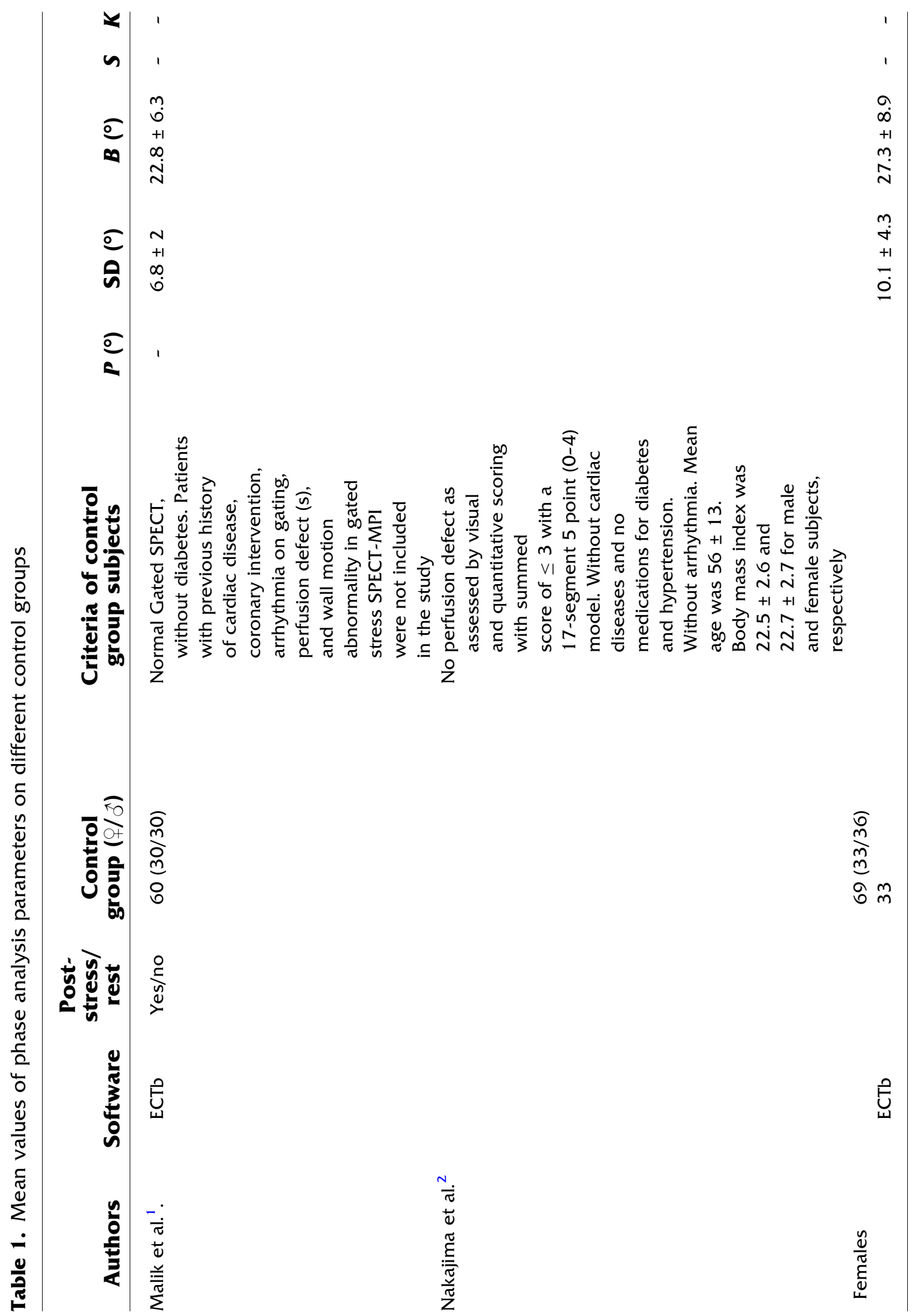




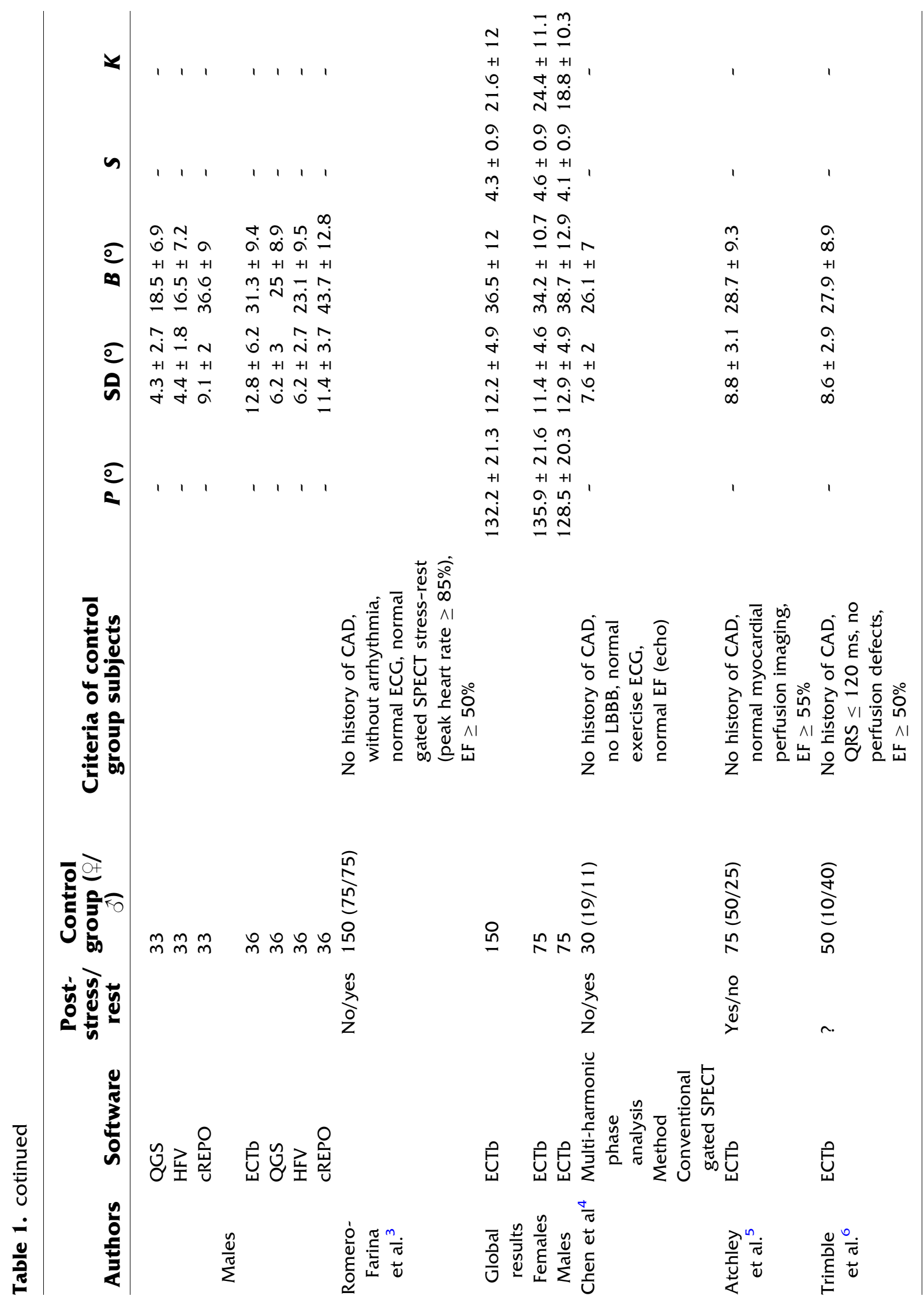


myocardial changes caused by diabetes directly, but also by the myocardial repercussion caused by the effects of DM on other organs (nephropathy, neuropathy, etc). Previously, From et al. ${ }^{22}$ evaluated the diastolic function in 486 patients with DM free of heart failure using tissue Doppler echocardiography, and concluded that a duration of DM of $\geq 4$ years is correlated with significant $\mathrm{LV}$ diastolic dysfunction. On the other hand, most of the asymptomatic diabetes patients with a 5- to 10-year duration of DM have ECG changes; $70 \%$ of patients with ECG changes have poor glycaemic control; $;{ }^{24}$ and the most common abnormality observed is ST-T changes, left atrial enlargement, left ventricular hypertrophy, left bundle branch block, and right bundle branch block. ${ }^{24}$ In other study, ${ }^{23} 1760$ diabetic patients with a tissue Doppler echocardiographic assessment of diastolic function were identified; 411 patients $(23 \%)$ had diastolic dysfunction. The cumulative probability of the development of heart failure at 5 years for diabetic patients with diastolic dysfunction was $36.9 \%$ compared to $16.8 \%$ for patients without diastolic dysfunction $(p<0.001)$, and who had a significantly higher mortality compared to those without diastolic dysfunction. Also, these patients have an elevated risk for heart failure. The possible pathophysiological mechanisms between diabetes and heart failure may include a higher risk of atherosclerosis, microvascular dysfunction, and deposition of interstitial myocardial fibrosis, and specific neurohumoral deregulations. ${ }^{25}$ Höke et al. ${ }^{25}$ studied 710 patients with diabetes with heart failure and cardiac resynchronization therapy. At the 6-month follow-up, they found a significant $(p<0.001)$ improvement in diastolic and systolic function after cardiac resynchronization therapy. Therefore, the evolution time of the diabetes is very important, because the longer the exposure to diabetes, the higher the prevalences of myocardial involvement.

Furthermore, another interesting aspect of Malik et al's. ${ }^{1}$ work, is the association between diabetes, arterial hypertension, and ventricular hypertrophy. The left ventricular hypertrophy and remodeling is frequent in patients with type II DM; cardiac steatosis and impaired myocardial energetics can contribute to these changes. ${ }^{26}$ Interstitial fibrosis is implied in the pathogenesis of ventricular hypertrophy, and was identified in advanced stages of diabetic cardiomyopathy. ${ }^{26-28} \mathrm{DM}$ per se is linked to significant cardiac steatosis, and there exists a correlation between myocardial triglyceride and the concentric ventricular remodeling. Also, the myocardial steatosis is a predictor of concentric LV remodeling and subclinical contractile dysfunction in patients with type II DM. ${ }^{26}$

All this explains how complex it is to study the ventricular dyssynchrony in DM patients. In future 


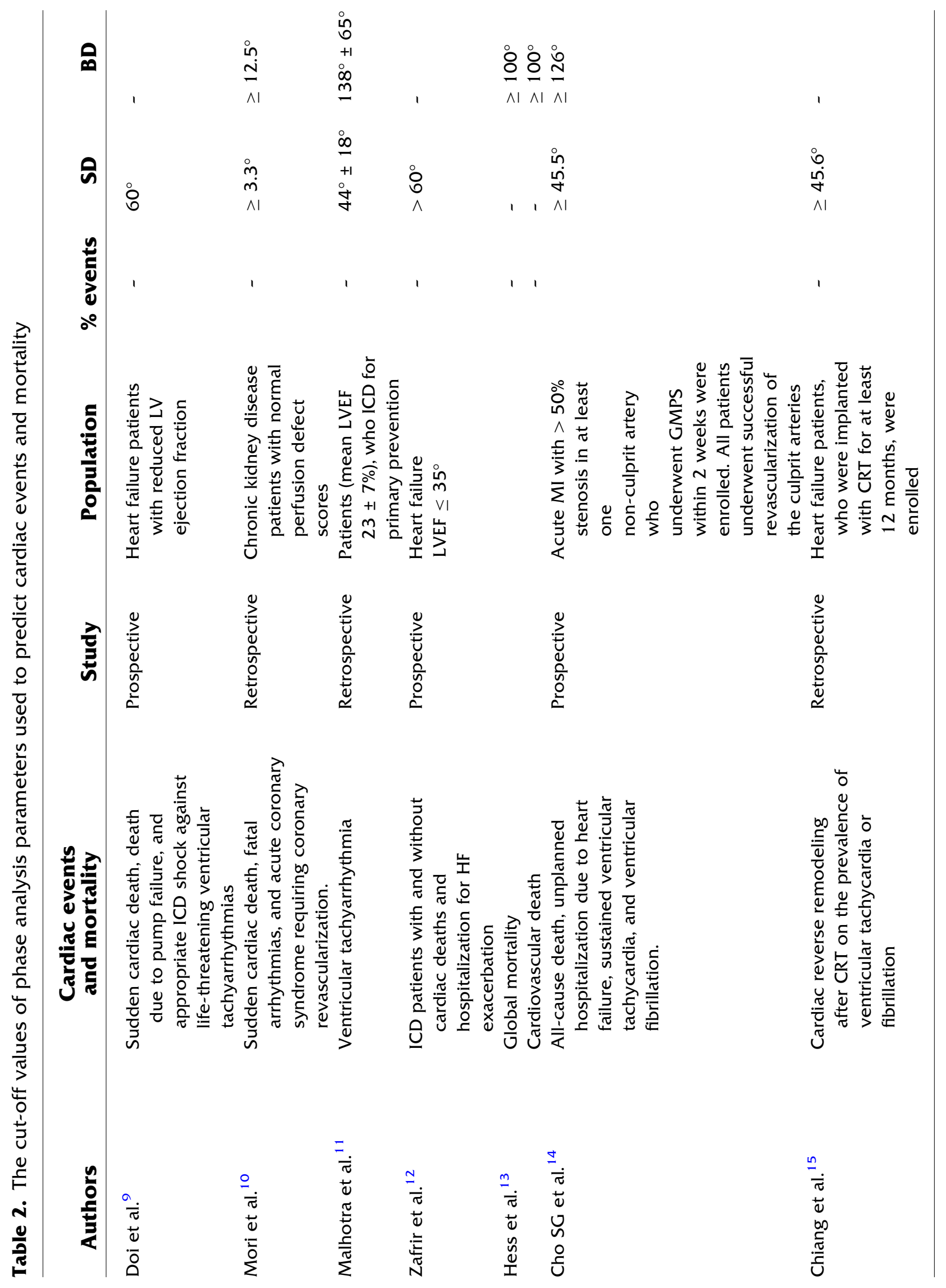




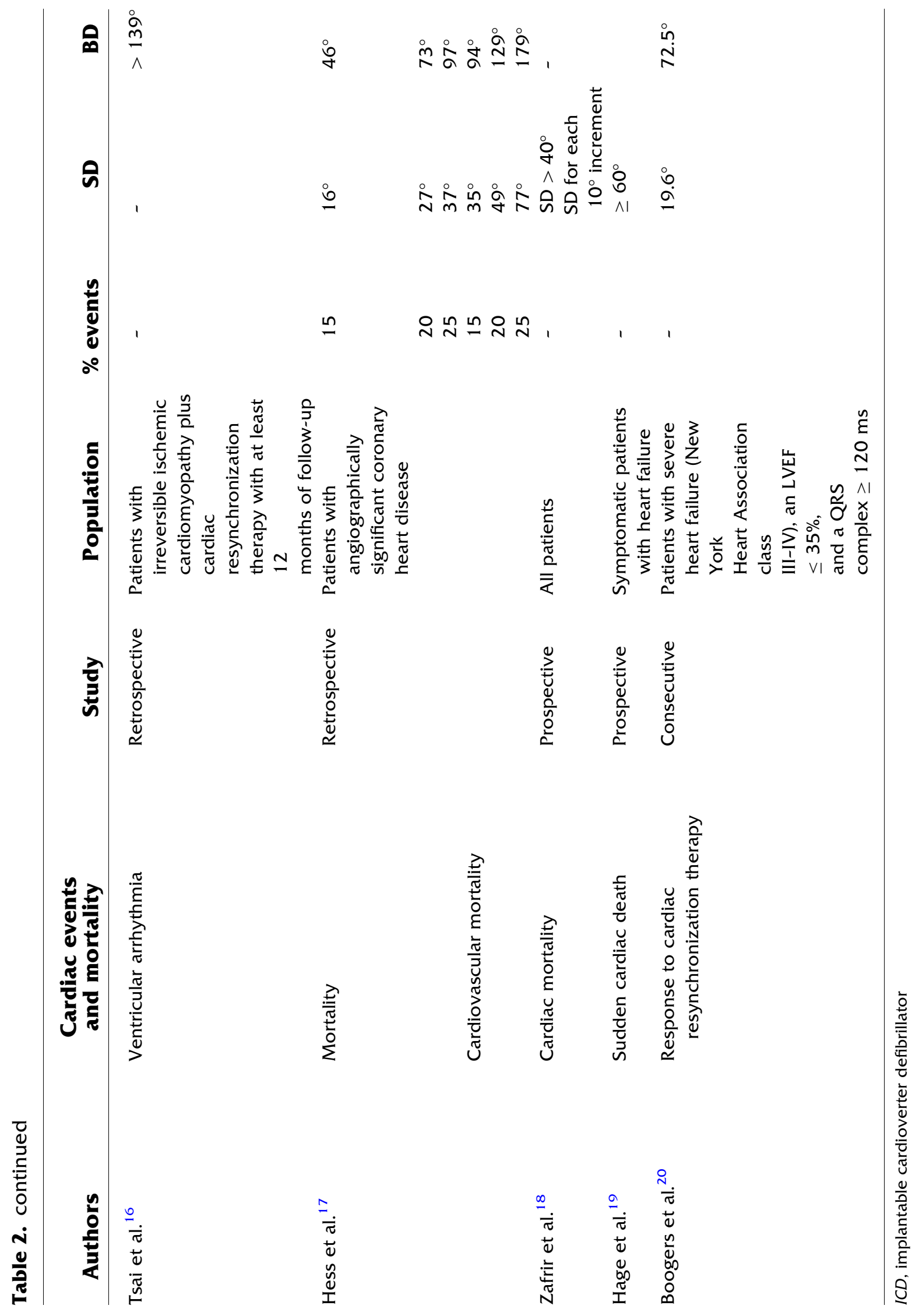




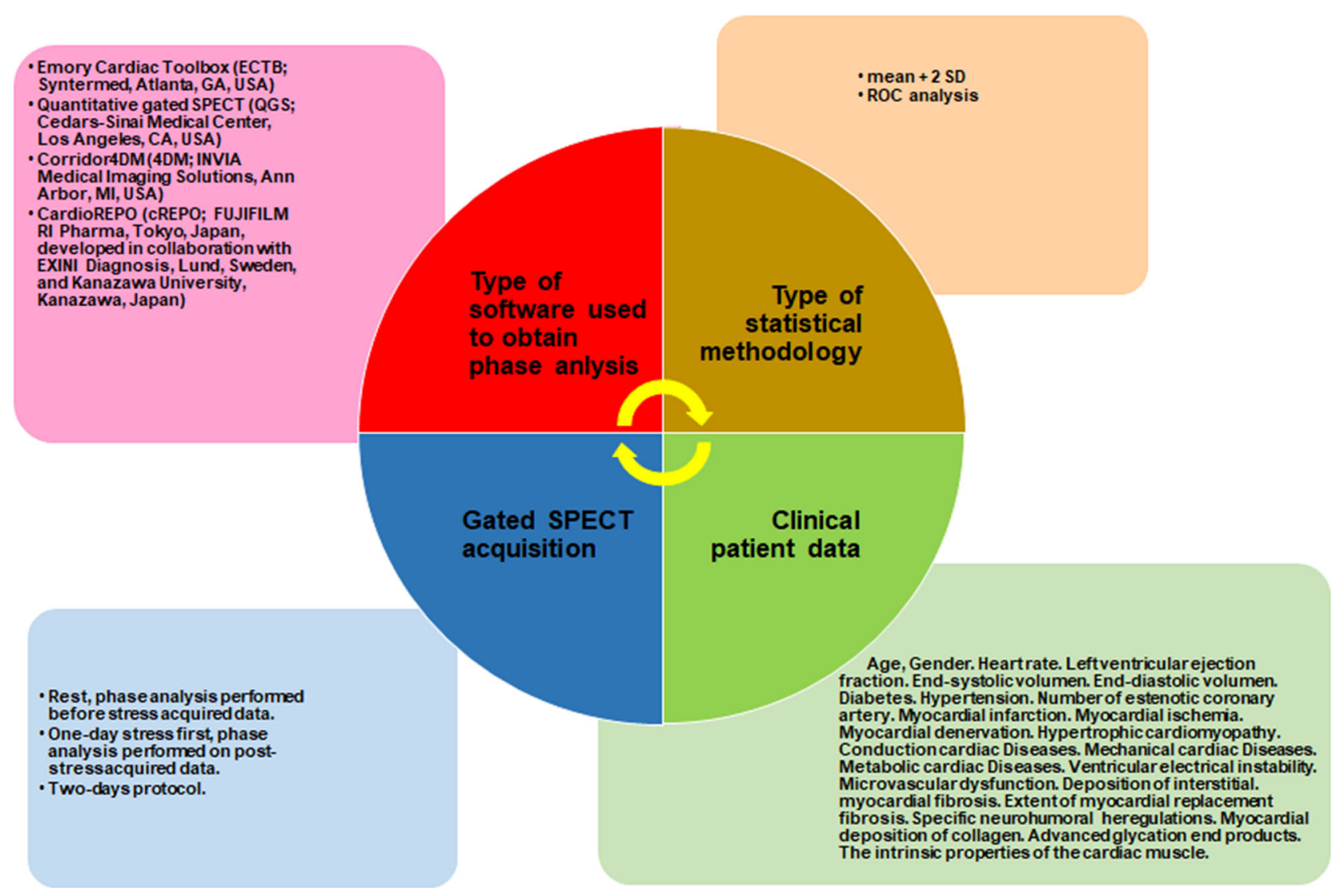

Figure 1. Variables that have the same goal: influence on the analysis of ventricular synchrony.

studies, to avoid these confounders (nephropathy, neuropathy, arterial hypertension, ventricular hypertrophy, etc.) in DM patients, it is very important to exclude patients with diabetic complications, but this requires a greater number of patients to be evaluated.

Noteworthy, in the current issue of the journal, ${ }^{1}$ this study is titled "left ventricular mechanical dyssynchrony assessment in long-standing type II diabetes mellitus patients with normal gated SPECT-MPI." All patients have a normal gated SPECT. To consider a normal gated SPECT, it is important to have a normal synchrony. Actually in our Nuclear Cardiology Department, we define a normal myocardial perfusion gated SPECT stress-rest as normal perfusion, motility and thickening (score 0), normal volumes, normal ejection fraction, normal transient ischemic dilation ratio, normal chape index, normal stress lung-heart ratio, normal synchrony, normal coronary flow, normal coronary reserve flow, normal ST, without angina, $\geq 5$ METs, normal heart rate recovery, normal $\%$ heart rate $(>80 \%)$, normal reserve pulse pressure, and normal Duke treadmill score.
According to these considerations, perhaps in future, research studies should use the same methodology and the same adjustment variables to obtain the normal cutoff values of phase parameters. Finally, we recognize the effort and enthusiasm of Dr. Malik and the rest of the authors in the preparation of this research work.

\section{Disclosures}

The authors report no potential conflict of interest relevant to this editorial.

\section{References}

1. Malik D, Mittal B, Sood A, Parmar M, Kaur G, Bahl A. Left ventricular mechanical dyssynchrony assessment in long-standing type II diabetes mellitus patients with normal gated SPECT-MPI. J Nucl Cardiol. 2018. https://doi.org/10.1007/s12350-018-1208-9.

2. Nakajima K, Okuda K, Matsuo S, Kiso K, Kinuya S, Garcia EV. Comparison of phase dyssynchrony analysis using gated myocardial perfusion imaging with four software programs: Based on the Japanese Society of Nuclear Medicine working group normal database. J Nucl Cardiol. 2017;24:611-21. 
3. Romero-Farina G, Aguadé-Bruix S, Candell-Riera J, Pizzi MN, García-Dorado D. Cut-off values of myocardial perfusion gatedSPECT phase analysis parameters of normal subjects, and conduction and mechanical cardiac diseases. J Nucl Cardiol. 2015;22:1247-58.

4. Chen J, Kalogeropoulos AP, Verdes L, Butler J, Garcia EV. Leftventricular systolic and diastolic dyssynchrony as assessed by multi-harmonic phase analysis of gated SPECT myocardial perfusion imaging in patients with end-stage renal disease and normal LVEF. J Nucl Cardiol. 2011;18:299-308.

5. Atchley AE, Trimble MA, Samad Z, Shaw LK, Pagnanelli R, Chen $\mathrm{J}$, et al. Use of phase analysis of gated SPECT perfusion imaging to quantify dyssynchrony in patients with mild-to-moderate left ventricular dysfunction. J Nucl Cardiol. 2009;16:888-94.

6. Trimble MA, Velazquez EJ, Adams GL, Honeycutt EF, Pagnanelli RA, Barnhart HX, Chen J, et al. Repeatability and reproducibility of phase analysis of gated single-photon emission computed tomography myocardial perfusion imaging used to quantify cardiac dyssynchrony. Nucl Med Commun. 2008;29:374-81.

7. Trimble MA, Borges-Neto S, Smallheiser S, Chen J, Honeycutt EF, Shaw LK, et al. Evaluation of left ventricular mechanical dyssynchrony as determined by phase analysis of ECG-gated SPECT myocardial perfusion imaging in patients with left ventricular dysfunction and conduction disturbances. J Nucl Cardiol. 2007; 14:298-307.

8. Chen J, Garcia EV, Folks RD, Cooke CD, Faber TL, Tauxe EL, et al. Onset of left ventricular mechanical contraction as determined by phase analysis of ECG-gated myocardial perfusion SPECT imaging: Development of a diagnostic tool for assessment of cardiac mechanical dyssynchrony. J Nucl Cardiol. 2005;12:68795.

9. Doi T, Nakata T, Yuda S, Hashimoto A. Synergistic prognostic implications of left ventricular mechanical dyssynchrony and impaired cardiac sympathetic nerve activity in heart failure patients with reduced left ventricular ejection fraction. Eur Heart J Cardiovasc Imaging. 2018;19:74-83.

10. Mori H, Isobe S, Suzuki S, Unno K, Morimoto R, Kano N, et al. Prognostic value of left ventricular dyssynchrony evaluated by gated myocardial perfusion imaging in patients with chronic kidney disease and normal perfusion defect scores. J Nucl Cardiol. 2017. https://doi.org/10.1007/s12350-017-0889-9.

11. Malhotra S, Pasupula DK, Sharma RK, Saba S, Soman P. Relationship between left ventricular dyssynchrony and scar burden in the genesis of ventricular tachyarrhythmia. J Nucl Cardiol. 2017. https://doi.org/10.1007/s12350-017-1095-5.

12. Zafrir N, Bental T, Strasberg B, Solodky A, Mats I, Gutstein A, et al. Yield of left ventricular dyssynchrony by gated SPECT MPI in patients with heart failure prior to implantable cardioverterdefibrillator or cardiac resynchronization therapy with a defibrillator: Characteristics and prediction of cardiac outcome. J Nucl Cardiol. 2017;24:122-9.

13. Hess PL, Shaw LK, Fudim M, Iskandrian AE, Borges-Neto S. The prognostic value of mechanical left ventricular dyssynchrony defined by phase analysis from gated single-photon emission computed tomography myocardial perfusion imaging among patients with coronary heart disease. J Nucl Cardiol. 2017;24:48290
14. Cho SG, Jabin Z, Park KS, Kim J, Kang SR, Kwon SY, et al. Clinical values of left ventricular mechanical dyssynchrony assessment by gated myocardial perfusion SPECT in patients with acute myocardial infarction and multivessel disease. Eur J Nucl Med Mol Imaging. 2017;44:259-66.

15. Chiang KF, Hung GU, Tsai SC, Cheng CM, Chang YC, Lin WY, et al. Impact of cardiac reverse remodeling after cardiac resynchronization therapy assessed by myocardial perfusion imaging on ventricular arrhythmia. J Nucl Cardiol. 2017;24:1282-8.

16. Tsai SC, Chang YC, Chiang KF, Lin WY, Huang JL, et al. LV dyssynchrony is helpful in predicting ventricular arrhythmia in ischemic cardiomyopathy after cardiac resynchronization therapy: A preliminary study. Medicine. 2016;95:e2840.

17. Hess PL, Shaw LK, Vemulapalli S, Pagnanelli R, O'Connor CM, Borges-Neto $\mathrm{S}$. An alternative method to examine the predictive value of mechanical dyssynchrony. J Nucl Cardiol. 2015;22:686-9.

18. Zafrir N, Nevzorov R, Bental T, Strasberg B, Gutstein A, Mats I, et al. Prognostic value of left ventricular dyssynchrony by myocardial perfusion-gated SPECT in patients with normal and abnormal left ventricular functions. J Nucl Cardiol. 2014;21:53240.

19. Hage FG, Aggarwal H, Patel K, Chen J, Jacobson AF, Heo J, et al. The relationship of left ventricular mechanical dyssynchrony and cardiac sympathetic denervation to potential sudden cardiac death events in systolic heart failure. J Nucl Cardiol. 2014;21:78-85.

20. Boogers MM, Van Kriekinge SD, Henneman MM, Ypenburg C, Van Bommel RJ, Boersma E, et al. Quantitative gated SPECTderived phase analysis on gated myocardial perfusion SPECT detects left ventricular dyssynchrony and predicts response to cardiac resynchronization therapy. J Nucl Med. 2009;50:718-25.

21. Dedkov EI, Bogatyryov Y, Pavliak K, Santos AT, Chen YF, Zhang $\mathrm{Y}$, et al. Sex-related differences in intrinsic myocardial properties influence cardiac function in middle-aged rats during infarctioninduced left ventricular remodeling. Physiol Rep. 2016. https://doi. org/10.14814/phy2.12822.

22. From AM, Scott CG, Chen HH. Changes in diastolic dysfunction in diabetes mellitus over time. Am J Cardiol. 2009;103:1463-6.

23. From AM, Scott CG, Chen HH. The development of heart failure in patients with diabetes mellitus and pre-clinical diastolic dysfunction a population-based study. J Am Coll Cardiol. 2010;55: 300-5.

24. Gupta S, Gupta RK, Kulshrestha M, Chaudhary RR. Evaluation of ECG abnormalities in patients with asymptomatic type 2 diabetes mellitus. J Clin Diagn Res. 2017;11:39-41.

25. Höke U, Thijssen J, van Bommel RJ, van Erven L, van der Velde ET, Holman ER, et al. Influence of diabetes on left ventricular systolic and diastolic function and on long-term outcome after cardiac resynchronization therapy. Diabetes Care. 2013;36:985-91.

26. Levelt E, Mahmod M, Piechnik SK, Ariga R, Francis JM, Rodgers $\mathrm{CT}$, et al. Relationship between left ventricular structural and metabolic remodeling in type 2 diabetes. Diabetes. 2016;65:44-52.

27. Weber KT, Brilla CG. Pathological hypertrophy and cardiac interstitium. Fibrosis and renin-angiotensin-aldosterone system. Circulation. 1991;83:1849-65.

28. Rubler S, Dlugash J, Yuceoglu YZ, Kumral T, Branwood AW, Grishman A. New type of cardiomyopathy associated with diabetic glomerulosclerosis. Am J Cardiol. 1972;30:595-602. 